\title{
The Concept Of The Body In The Contemporary Global Formation
}

\author{
Assist proof .Dr. Ahmed Khlaif Mankhi \\ Maysan University / College of Basic Education / Department of Art Education
}

Ahmed44kms@gmail.com

Article History: Received:11 January 2021; Accepted: 27 February 2021; Published online: 5 April 2021

\begin{abstract}
The current research deals with the concept of the body within the framework of the global formation because of its great potential for significance and expression according to the aesthetics of our current era within the conceptual and intellectual system intertwined between truth and imagination to reconfigure reality with the vision of the artist of the present age, so that the body has become a present element in the modern formation with a physical presence after If it was just copies of reality executed with different materials, then the artist invested the expressive energies of the body in the second half of the last century as distinct works of art.
\end{abstract}

\section{Chapter One: Introduction}

The body is the oldest means of expression known to man, whether it is a phoneme, gesture, or kinetic expression. Every expression through a specific context represents a sign of a specific event or action, so the human bodies in the first primitive societies were naked or semi-naked, so this era had means of expression of its own and the course of time and learning From his experiences, he became more sophisticated, so he knew the use of tools and the skill of his hand became much better than in the past, so his expressive methods were better, so he seemed to use cave walls for expression as an economic and magical way to control animals, but it was not without expressive creativity and artistic distinction, and his body gradually transformed from nudity to cover Simple clothes that are considered a fashion in their age and also began to develop their language, thus becoming in contact with the most advanced societies represented in the first civilizations that respected the human body and sanctified it and depicted the gods in the form of human beings because they found the human body the most beautiful and complete something in existence, especially in the civilization of Mesopotamia and the Nile Valley where it was photographed VIPs, heroes and gods in an exemplary style free from defects, the features do not contain any emotion. I only care about the movements of the human body. This tradition extended to the Greeks by excluding For the expressions and emotion on the faces of people and their interest in the human body and being beautiful, they depicted it naked and created ideal proportions for the body free from defects, so they invented the Olympic Games to glorify the human body through their athletic heroes and their concepts were transferred to the Renaissance, but the Italian artist added to the Greek predecessor what suits his era and art was developing on Slow pace across art schools and is considered a paradigm shift by the claude monet in modern art through the painting The Luncheon on the Grass by depicting a naked girl within the painting, as it is an objection to the exclusion and marginalization of the body and a number of lesser value than thought, the artist's struggle continued with a struggle to display the body as an aesthetic form My expression without employing his physical energies such as sound and movement in the global formation, and when the twentieth century passed by the economic shocks and colonial competition that left two world wars that destroyed the whole world and the emergence of many movements, especially in the sixties and seventies of the last century, all this changed the concepts of art and art became more human It expresses humanitarian issues, so many schools and artistic trends emerged, and one of these trends employed the human body as a material for contemporary art in ways of displaying and performing Different in line with the style, direction and method of presentation, so the artist replaced wood, stone and metals to produce creative contemporary artistic works. Through the above, the following question is raised: How did the concept of the body become in the contemporary global formation?

The importance of the research is that it tries to identify the concept of the body in the contemporary global formation. The research is determined by the year 2019-2020 and the spatial boundary in Europe and America, and the objective limit is to know the concept of the body in the contemporary global formation.

Keyword (concept, body, formation)

Define terms 
The body linguistically: the body (Al-Razi, 1986, page 44)

Idiomatically: every perceived physical presence ... resides in the place. (Laland, 2008, p. 231) The concept of the human body is shaped by the presence of the soul in it. (Laland, 2008, page 232)

It is an extension of the essence with three dimensions and consists of matter and form ... characterized by life as the living beings in existence, such as plant and animal. (Saliba D., page 402)

Operatively: It is the physical presence of a person in this world.

Linguistically speaking, form: form: form. (Abadi, 2008, page 1019)

Idiomatically: everything that is formed by a certain force on matter to be a certain shape (Laland, 2008, p.323)

Procedurally: All that the artist does in terms of changing and employing the material, whether natural, artificial, live or inanimate, to produce a work of art.

Linguistically Contemporary: The Age: Today

Idiomatically: it is the simultaneity in one era of various events and facts. (Al Kafi, page 407)

Procedurally: all the actions, achievements, facts, and events that occur in society in a certain period of time.

The second chapter: The first topic

The concept of the body in the philosophical field

The body was and still excites philosophers through the ages from Greek philosophy until today, when exclusion and exclusion were practiced on it, so we perceived it as a purely physical existence and all knowledge that comes through the senses as it is linked to the physical existence of the body so it is considered unreal. For the mind and the thought, and response philosophers came to consider the body and the human values that originate in the human body. Socrates found the mind to be higher than the body by adopting the principle of (Know yourself by yourself) that is meant by the person looking at the inside and not his form and physical existence because the soul is the one that contains the mind and the mind is the center of the truth. (Qasim D., 2002, p. 23) No matter what bodily capabilities we have reached, they remain formal and do not achieve sophistication or sublimity, and they are the source of pseudo-material pleasure, thus linking the body with fleeting desires as they are linked to emotions, imagination and purely material constants, and through that, the mind is the source of access to the truth. Reaching out to solve the problems that face us through mental debate. Socrates sees the body to submit blind obedience to the mind, and the body must be tempered for that as it does. (Karam, page 68) He tries to make man's decisions wise and not reckless by making his life go according to a rational pattern that mixes the mind and the soul. The mind gives control over the senses and organizes them according to a specific system. (Karam, page 71) The blending of the soul with the body There must be a control that regulates its interaction with the physical reality in terms of behavior and actions.

Plato sees a separation between the soul and the body as they are two different entities. The soul is immaterial, linked to the mind, as it does not age or is affected by time. As for the body, it is a physical entity that is affected by the factors of time. Both are not equal, and there is no similarity or convergence between them. (Qasim D., 2002, p. 32) Plato sees the soul connecting between the realm of pure and eternal truths that are part of it that has left it and the material world it is locked in with which it is trying to leave. (Qasim D., 2002, p. 34) Perhaps the cause of the conflict between material desires and mental transcendence is this connection between an ideal world and a material world in the body.

Aristotle disagreed with the separation between the body and the soul, and he considered them one thing as the impossibility of separating between them, for both of them complete the other as in the statue, so the body is its physical presence and the soul is its image, and their separation is only by destroying the statue. (Qasim D., 2002, p. 68) The body without the soul is called a corpse, and there cannot be a soul alone, as it has no specific shape that can be recognized. If there are two different worlds that the body contains, how can something non-physical to see, feel, speak and think of Without a physical presence, how can that happen in the absence of feeling? The mind can only 
perceive it through mental or imaginary images because it is a kind of non-material feeling. (Qasim D., 2002, page 70)

As for Descartes, he disagreed with Aristotle and agreed with Socrates and Plato that reason is superior to the body. According to (cogito) Descartes, existence is present through a temporal concordance between consciousness and existence to reveal the transcendence of consciousness by which it perceives the essence of physical existence through the intended ego, the soul that distinguishes the body. (Tibis, 2009, p. 155) Through mental thinking related to the soul, we are aware of this world around us, for we ourselves and not others' selves through which we are aware of the present, so the material that extends to the body cannot take place in the awareness process of the special self-presence and thus the body becomes dependent on the soul to carry out what it orders. Descartes Thinking, i.e. consciousness, is the tool of the ego, and it is what distinguishes a person as a rational, thinking being from others, so the body becomes a tool for her. Here, the presence is not the physical presence but what it contains of the soul represented by the ego. (Tibbs, 2009, page 155)

Spinoza rejected the idea of the body at the disposal of the soul, which is the source of the truth, and that it is higher and better than the body. He considered man a unified entity in which there are no so-called mental perceptions and sensory perceptions, as the body moves and acts simultaneously with the desires and whims of the soul, so the desires of the human being themselves are the desires of the body and soul together. (Al-Talili, 2009, page 155) He rejected the duality of body and soul and considered them to be one thing, appearance and essence.

Nietzsche believes that it is not possible to exist in life without the body, for the self is in the body ... our presence is represented in this material world and it is the reason for the continuity of our existence. The thought process, the thought system, or related to the human being is not to live. Thought and capabilities of thinking cannot be counted as a condition of existence. (Al-Talili, 2009, page 159)

Man falls into Heidegger's philosophy under his immediate term, which is one of the manifestations of existence and is summarized as follows:

- Existence in this world between the existing assets with what happens with them in terms of interactive relationships ... and this existence is my existence, my life is connected with others, and this is embodied by the existence of a physical or physical existence capable of interaction with others in this world.

- Existence with others and it is called the true or authentic hejjar, it enables the self to feel himself and is responsible for what achieves its existence by holding responsibility for that. Among people, you are forced to imitate them.

The anxious existence is here on the existential connotation that reveals itself about the self and its relationship with the world through its openness to it through a feeling of anxiety. The reality of the existence of the Ego is revealed as being thrown into the world despite its will. (Kamil, 2016, page 94) The human being is a social being who integrates his body with others and interacts with the world with his assets, so he gets to know what surrounds him with his physical presence and not the mental, so he finds there are problems and things that offend and threaten him, which made him anxious and this anxiety is positive that makes him fluent in dealing with problems That surrounds him and creates solutions to make his life easier and better.

Sartre finds the body to be an apparent existence of the other just as the body must exist for itself ... and since the world appears the body visibly as a consciousness of the world, and the body as a self-existence, the body is in terms of consciousness in terms of its physical formation as awareness of the world (Al-Sharouny, 2009) Page 79) It is not possible to recognize existence except through physical attributes, so that I feel my body and what it feels about the bodies of others through the senses and physical characteristics, so the body feels its presence as a physical existence through consciousness.

The body according to Merleau-Ponty is an activity and behavior based on meaning, it is related to all the expressions that come from the body if they are signs, movements, or positions (Al-Zawawi, 2009, page 134). The body cannot be identified except through its activity and behavior, it transmits indications and if it is otherwise It does not hand a human body but something else. The body defines its status in the world according to the ability it has to accomplish meaning and expression, and this distinguishes it from things because awareness of the special body must have meaning and meaning is related to the possibility of expression and the body must be present in all 
foci of meaning as it is the source of meaning. (Al-Zawawi, 2009, page 136) The physical presence is not only a physical presence, but rather a communicative presence through different communication channels during human activities, as every action achieves signs and symbols that have specific connotations through a specific context that interpret to understand their meaning.

\section{The second topic}

The concept of the body in contemporary art

The body is the oldest means of expression known to mankind since the emergence of man on the face of the earth, whether to express feelings or a certain situation, as well as the religious rituals that were practiced by shamans and priests in the temples in the form of certain dances and movements, then the body transformed into a means in the hands of authority either for suppression or the practice of certain actions, whether Military, religious, or compulsory work in favor of the king or those with influence, but at the present time the body has become a symbol of freedom, temptation, beauty, elegance, perfection, sophistication and culture, so it has become a means of expression in various and varied means and methods that reflect contemporary human behavior and what it feels about the changes of the era stifling space Its freedom, exclusion and marginalization has become a kind of personal expression, as some decorate their body in different ways and methods, and the body possesses the dynamism in diversity by employing raw materials to produce artistic works that mimic the language of its time embodied in the human body and its contents and enormous expressive energies are unlimited. So the body becomes the material to form or Embodying an artistic work, meaning that it became the direct mediator between it and the audience or viewers. The sixties of the last century witnessed the start of the Fluxus movement, which relied on the Direct performances to the audience. The performances of this trend combined dancing, reciting poetry pieces and certain movements, as it relied on spontaneity, encouraging the contemporary artist to pay attention to the importance of the body in the contemporary intellectual system. Body art was launched as one of the types of conceptual art, including the performance art, which is based on what the artist presents from a performance act alone or with the participation of other people or involves the attendees as part of the show. The presentation may be directly in front of the audience or indirectly, filmed by video and presented to viewers.

Actress Carolee Schneemann presented nude works of art in a spontaneous theatrical style that displays directly to the public in many of her works that use different materials as part of her performances.Sometimes she uses these materials and sometimes puts them on her body to be a piece of art as in her work (Eye Body) (Figure 1) We find the body intertwined with substances that made man a part of the commodity world, or that it is a commodity on demand and fragmented with its multiple reflections by the action of mirrors to confusion and differences in viewpoints, so that prejudices are released according to what he sees from his angle only, and this is one of the issues of contemporary man. In her work (Up to and Including Her Limits), she was attached to a rope on the ceiling, placed huge papers on the wall and the floor, and drew lines on the papers with their suspended movement in all places and directions that she could reach.

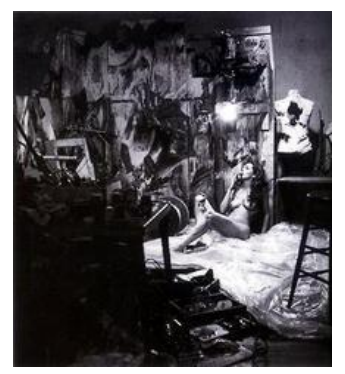

(Figure 1)

Joseph Beuys presented philosophical propositions in an artistic framework and in a simple manner sometimes by showing in front of the audience by giving lectures and concepts and being a professor. Explain Pictures to a Dead Hare.

As for the artist Chris Burden, he was an extremist in his performances, as he presented a type of masochis with live performances, as he created a new concept that simulates his artistic visions of contemporary reality, and he presents 
it as a cruel exercise on his body, making him the field of performance experimentation, as he tries to say that art is illogical of the types of art, it can be said that the rediscovery of pop art is not a popularly circulated metaphor of tools, products and public figures, but rather a metaphor for violent behavior and daily incidents and from his works (immediately after peforming shoot) in this work he presented himself with a gunshot.

In the works of the artist Marina Abramovic, she presented some interactive live performances with the audience, and some of her performances are presented alone. In her performances, she provides an insight on the concept of human relations in society (figure 2). One of the audience for a minute, and the audience seemed to wait in line to sit for a minute in front of the artist, only out of curiosity. We find that what the artist presented is the force of the curiosity motive that drives us to discover things even if they are not of interest or have a benefit. Mind and physical body that makes him stand for a minute in front of a body that has not moved for a period approaching four days, so he thinks whether he will stand up or remain focused and energetic, will he continue with the same enthusiasm without food or water or relieve himself? Is he suffering from pain in the back and feet from the length of sitting? A type of relationship between the audience and the artist, what he thinks when sitting in silence, and a lot of questions that arise about the capabilities and capabilities of the body.

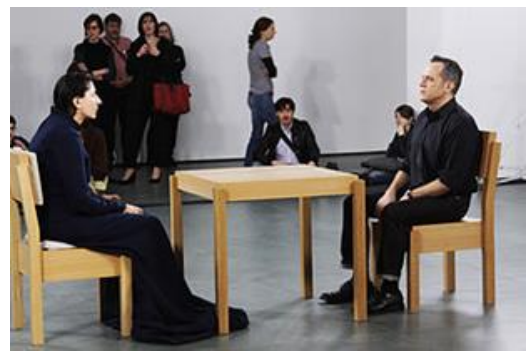

(figure 2)

The French artist Pierre Huyghe presents a performance show called "The Third Memory" (Figure 3), which is a reenactment of an American film of a bank robbery here. The artist performs an attempt to reproduce or imitate a scene stuck in his memory. The idea of the presented work is memory and reformulating it on the ground in a physical form. Tangible, it is a physical evocation by a pictorial medium. Here the question is related to the illusion, reality, imagination and truth. Likewise, time and being aware that the past cannot be repeated, the work is nothing more than a remembrance of the body's existence in a past time, of which only memories remain.

As for body paint, artists have been pushed to change the outward form of the body with slowness and employment as a contemporary work, and many artists have found this type of body art to meet their artistic aspirations. Here the artist uses the body as a material to achieve an artistic work(figure 3), and the specificity of this art is temporary and not always documented with photographs to remain, meaning that it disappears at the end of the show. Among the artists of this type of body art is the artist Alexander Khokhlov, who is distinguished by his interest in human faces, which are predominantly feminine. He has varied stylistically coloring faces, as he simulates contemporary artistic schools, meaning the artist restores the styles of those artistic trends on vivid models to achieve a contemporary artistic vision, but despite the tradition For a specific style, however, the contents and visions differ radically as it was carried out on a living three-dimensional body and not on a two-dimensional surface, so we find in simulating the cubic style, except that he added the red and Ukrainian colors to it to move away from stagnation and to give vitality, meaning that it added privacy to The figure did not imitate a blind imitation, when we contemplate the figure, we find it similar to the female faces of Picasso, which he painted in his paintings during the stages of Cubism, we find the work that simulates visual art or digital images with The time is not high, he did this through the gradation of colors in the form of squares, which gave a confusing visual effect to the eye that suggests blurring. The artist presented the face in a pop art style, using a variety of colors in addition to sticking paper clips on the face and neck and using pieces of newsprint on the head. Without changing it, it did not add colors, as well as leaving color intensities on the face. 


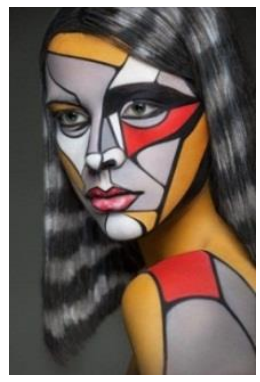

Figure (3)

As for the artist Jean Paul Bourdier's method of treating the human body and making it part of nature or interfering with it, the artist prefers natural open spaces to form his works of art by making them in harmony with their natural surroundings in different ways and treatments according to the subject. In the Bodyscapes series, we find in (Figure12) treat the figure The human being by making him complement the scene or be part of it, as he treated the two female bodies from the bottom with a green balloon that simulates the plant and formed part of it, and then he drew the shape of the trees and distant mountains, then the color of the upper part of the blue balloon simulates the color of the sky, so the two bodies became transparent. Everything behind them can be seen, but he left hair The head is black without treatment. If he treated them with the color of the sky, it would be difficult to distinguish them from the landscape in front of us, and we find a treatment for the human body.

The artist Spencer Tunick presents panoramic displays in his artistic works, as he relies on large crowds of naked bodies according to an accurate and thoughtful epic organization and direction. As buildings or in natural places.

Tattoo is one of the arts in which the artist relies on shaping the body using special inks and is very popular in society, attracting both sexes and is distinguished by its permanent status and does not fade with the passage of time. The British artist, Louis Molloy, is one of the famous tattoo artists. It has a special style. It is famous for being a tattoo of the international player David Beacham. Or influenced by Japanese and Chinese tattoos in terms of shapes and colors, as in The Ninth Legend, his works combine realism and symbolism.

The artist, Steve Butcher, is one of the artists who relies on the method of Super realism in the implementation of his artistic works on the body and many works dealing with public figures such as athletes and artists as well as various other topics with very high accuracy to express a special style in Kobe Bryant the American basketball player as a picture Photographic, where he paid attention to all the details and in his work Insanely Good, a paper that is no less wonderful and creative than the previous currency that expresses the American style of basketball.

\section{Chapter III}

Search procedures

research community

Represent the research community in the artworks completed in the year 2019-2020 in Europe and the United States of America through investigation and research to obtain research samples from the World Wide Web.

The research sample

3 samples were counted in an intentional manner consistent with the research objectives and the distinct artistic presence of the artists on the European continent and the United States level, and one sample was chosen that represents the artistic direction in which the body appears.

Search tool, methodology

The researcher relied on observation in tracking and revealing the features of the appearance of the body in the contemporary global formation. 


\section{Research Methodology}

The descriptive and analytical approach was adopted in terms of the use of the material, the methods of formation, the technique and the method of presentation.

Sample analysis

Artist: Milena ZeVu

Business Name: In Light A Journey Into the Unseen 2020

Year of production: 2020

Country: Serbia

The artist presented the struggle of the body with reality, including the difficulties and obstacles it encounters during life, so she appeared in tight white clothes, wearing a white muzzle on her head, similar to the strap that Ninja fighters put on their heads, and then putting two black lines under her eyes, as America's indigenous people do when preparing for or fighting war. The artist used her body as an expression of what is happening in our world today, as it is almost stopped. The fight against the Corona virus is here. The link is through the metaphor of the muzzle that people use today for protection, as it is a sign of fear, so she used it as a symbol of challenge and confrontation instead of fear and protection, and the color of her white clothes indicates hope for a world in darkness And the pessimism must be removed through the light. Here we see the graceful and beautiful body of the artist performing normal movements that we do every day, especially women by sitting in front of the woman to adorn when she put the two black lines on her beautiful face, this is a sign that the body is beautiful at all times, whether it is war, crises or times Stability and comfort is only required to pay attention to our bodies and look at them well. Often we neglect our bodies due to work pressures and obligations and focus on work and do not focus on our bodies despite what we look at ourselves every day in a mirror when going to work and do not look well at ourselves, so we do not notice the changes that occur. For our bodies due to aging or performing hard work except by accident, and this unintended neglect of the body we do not notice until after we are exposed to an accident, injury or disease, the body is unable to work and produce We are aware of the importance of our bodies. A white wall or a white space on a black wall appeared in the work. The largest books on it are at the top IN, then at the bottom of the left LI. He drew the stray of a person in black and then wrote HT on the right as if it was a mystery waiting for someone who had courage and feet. Here the artist stands In front of drawing the human shadow, we find the scene changed dramatically and beautifully, as it used to suggest depression, and it turned into a joyful scene due to the presence of the body, then the artist writes the letter G on her body, so the previously written phrase of the unknown meaning turns into IN LIGHT, and when the artist leaves the scene and disappears, the scene returns to the previous, vague, provoking The concern of the recipient is waiting for someone to take the initiative to stand as the artist did and write the letter $G$ to solve the puzzle, and this is the cycle of life that does not stop, but continues. A body comes and a body goes to infinity. However, wisdom is not by our passing through this life, but in what we left from the trace when leaving life. Our physical presence is embodied in memory through what we have presented to this life.

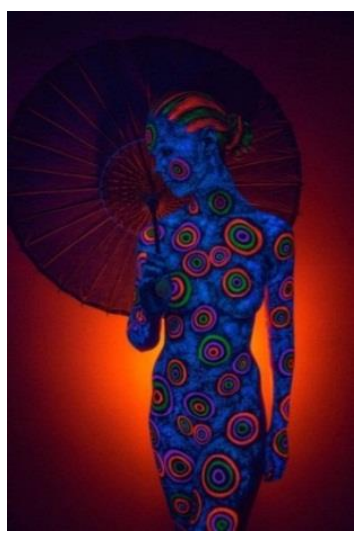




\section{Artist: Matt Deifer}

Business name: Circles is a painting

Year of production: 2019

\section{Country: United States}

The artwork appears in the form of a naked female body holding a Japanese umbrella, whose color ranges from black to dark brown, and the color of the female body is in circles in different areas of it on a light and dark blue background. Each circle contains a number of circles smaller, the circles get smaller as we go towards the center and each circle has a different color So my color contrasted with the background in which the body was colored, and there is light from behind the body, orange, which is a light color in the middle and ranges to darker color values between red and brown with the sides, and the lighting made the body stand out more distinctly from the background. Although the body is three-dimensional, the method of its coloring made it a two-dimensional surface, and the work appeared in general as a propaganda poster for an art exhibition. He used a simple method in terms of coloring the body and the idea. He did not use complexity, whether on the level of coloring the body using complex shapes and drawings, or adding another complementary mechanism. It was only satisfied with an umbrella. The artist was able to mentally arouse the recipient at the expense of the visual excitement of the female body, for he was absent from feminine details and all indications of femininity and tenderness depending on the mental excitement of what the recipient would ask questions about the meanings and contents of the work of art. Each technical, formal, and directive complexity thus achieved a special stylistic uniqueness. The artist presented a work of sobriety and creativity in line with his stylistic philosophy to create an impact on the recipient with a visual presentation that opens the way to the many disciplined interpretations and not the kind of interpretations that make the recipient run with the imagination of fertility mixed with something from Fantasy, but rather make the recipient artist somewhat follow a way to reach as much as possible to the intention The idea of the artist is not to find the recipient an idea and its meaning is far from what the artist wanted to say. The artwork is somewhat close to pop art. The work focused on the formal manipulation that creates visual diversity without distracting or fragmenting the shape, meaning that the recipient focuses on the human body, which was formed by a mixture of simplicity and visual manipulation codified according to simple repetitive forms that dominated the visual scene, so the body was shown in its complete coloring with a static and simple movement to show the strength of the personality and the presence of the body It appeared as a concept to form an aesthetically open visual formation that presents the subjectivity of the present body in the form of a mere subject of purely artistic propositions, so the artist tried to delve into the inner worlds of the body to draw up or make him suggest that it is an independent and autonomous present entity that imposes its presence with respect, far from sympathy. With the zeitgeist of the second decade of the millennium.

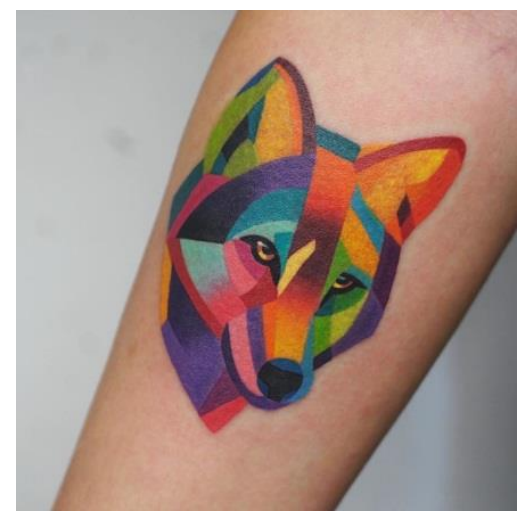

Artist: Sasha Unisex

Business name: prismatic wolf

Year of production: 2020

Country: Russia 
The work is in the form of a wolf's head by a girl, executed in a manner that blends reality and modernity, forming in the form of multiple color spaces between hot, cold and neutral colors, a feminine body overflowing with tenderness and quiet vitality. Despite the designation of the work and its shape as a wolf, but it is Also suggests that it is a bear. The tattoo is characterized by simplicity and dynamism, in line with the splendor of the era or the year 2020, which is an unforgettable year, as it is the year of Corona delinquency, so the sharp looks of the wolf, his being, the Corona virus, lurks us. When tattoos have become one of the features of our current era to express personality, liberation, strength and will in accordance with the concepts of our era characterized by change and rapid changes, the artist Sasha Unisex presented to us a temporary tattoo that gives freedom and great options in change and finding everything new that expresses youth. One of the most famous artists at the level of the year for the excellence and uniqueness she achieved. Through him the female qualities dominated the work, as the work occupied or occupied a small area of the arm of the model executed on the tattoo, so it appeared as a kind of amulet or a special logo associated with the model and this is a feature that the artist distinguished in most of her work The small ones are not interested in large works or that take large areas of the human body, and if they carry out large works, they leave empty spaces in tattoos, as well as most of their works are in true colors. She has works that have been carried out in one color, but most of them are colored works. We find the artist has a special view of the body by carrying out miniature works to arouse The recipient of small works in a manner that attracts attention to contemplate the body completely through a small part that occupies the tattoo, as it preserved the original shape of the body without change, as well as the entire tattoo can be seen without shortage That at all times, a part of it is not covered or obscured by the act of clothing or accessories, but if it is carried out in a large size, it will often not be seen completely and also cover the clothes, for example if it is carried out on the back it can be completely covered with clothes as well as the long hair of women, this in addition Large tattoos work from changing the shape of the human body due to the shapes and colors of tattoos, which changes the natural attractiveness and beauty of the human body. The tattoo is characterized by simplicity away from the ornamental, complex and full of details, symbols and shapes, as it has thus achieved its own style that distinguished it from other artists. She is looking for sources of inspiration for her from all cultures of the world, and this is what facilitated the development of her own style by achieving aesthetic purposes that blend with the human body to appear as an aesthetic icon that interacts with ancient art in the spirit and style of our time without losing anything of humanity or poetics of the female body, it is a kind of re The discovery of the body that has been obscured by the act of contemporary civilization and promised as a kind of commodity subject to supply and demand to work as a promoter of fabricated products that have emotional excitement and sexual connotations at the expense of humanity. Thus, the body can be considered an excellent material for practicing art, as it is unconventional and familiar to us. Every body we practice in artistic action remains beautiful, as every body has its symbolism and appropriate tattoo models, it depends on the nature of the personality, charisma, gender, as well as the extent of the artist's skill and ability are all factors that cause success tattoo and failed.

Research results

1- Performance art indirectly criticizes reality in an aesthetic conceptual framework.

2- Performance art and body paint depend on the simplicity of the idea to produce a work of art.

4- Contemporary formation is not concerned with nakedness of the human body, but rather with artistic, intellectual and aesthetic concepts that it presents.

5- Performance art and body paint need supplies and assistants and time to prepare for the show to materialize, unlike tattoo art that does not need assistants, a special place and many requirements.

6- Performance art and body paint are ephemeral.

7- Tattooing is distinguished by its persistence and lack of fading, but it loses its luster over time and becomes out of fashion in the future.

8- The body is more open to interpretation with infinite broad ranges, better than other materials used by the contemporary artist.

9- Art presents the body in an intellectual framework by introducing mental and intellectual concepts related to the mental and philosophical ideas prevailing in its era, and it is the most sincere art to express the era. 
10 - All body arts were associated with freedom, futility, and self-affirmation.

11- Arts overlap with each other by employing the body.

12- Art presents the body as an icon of the era that prides itself on values and concepts.

13 - All movements that appear in society, regardless of their intellectual, cultural and philosophical orientations, are reflected in the arts that deal with the body.

14 - The body sends in the context of contemporary art aesthetic, intellectual and social values.

15- Performance art, body paint, and tattoo suggest promotional and advertising connotations.

16- Performance art, body paint and tattoo presented the body as a ready-made thing in contemporary art formation.

17- Although the short period of time for Performance art and Body paint is limited, it is not subjected to live again.

Conclusions

1- A mixture of the body within the framework of art between artistic, intellectual, philosophical and aesthetic concepts.

2- There are arts that depend on the body to present the idea for a short period of time to criticize and analyze contemporary reality in an aesthetic framework through a documentary medium.

3- The artist was fully conscious of employing the body as a work of art because it has great potential for openness of meaning and plurality of vision.

4- Performance art, body paint and tattoo arts are a reflection of reality.

Sources

1. Al-Hassan Zawawi. (2009) The path to philosophy, Algeria, publications of the difference.

- Ismail Abdel Fattah Al-Kafi (without history) The Facilitated Encyclopedia of Contemporary Political Terminology www.kotobarabia.com.

- Andre Lalland. (2009) Lalland Philosophical Encyclopedia: Glossary of Critical and Technical Philosophy Terms (Khalil Ahmad Khalil, translator) Beirut, Lebanon. Aidat for publishing and printing.

2. Dr. Habib Al-Sharouni (2009) The Idea of the Body in Existential Philosophy, Dar Al-Tanweer for Printing and Publishing.

3. Djamel Saliba. (No date). Philosophical Lexicon. Relatives.

- Dr. Abd al-Rahman al-Talili (2009) Violence on the body, Alam al-Fikr magazine, Kuwait, Issue 4. Volume 37, The National Council for Culture, Arts and Literature.

4. Damhamed Fasim (2002) On the soul and the mind of the Greek philosophers and Islam. (3 ed.) The Anglo-Egyptian Library.

5. Majd Al-Din Bin Ya`qub Al-Fayrouzabadi (2008). Al-Famous Al-Muheet. (8 ed.) Beirut, Lebanon, AlRisalah Foundation.

6. Dr. Muhammad Kamel. (2016) The Judaism, Damascus, The Arab Book House.

- Muhammad bin Bakr bin Abd al-Qadir al-Razi (1986), Mukhtar As-Sahah, Beirut, Lebanon Library.

7. Youssef Karam (without history) History of Greek philosophy Cairo. Hendawi Foundation for Education and Culture.

8. -Dosef Tibbs (2009). The evolution of the concept of the body from philosophical contemplation to scientific conception. World Thought Magazine. Kuwait, Issue 4. Volume 37. National Council for Culture, Arts and Letters . 